\title{
ALTERNATIVE MANAGEMENT APPROACHES: LEAN SIX SIGMA
}

\section{DOI: 10.17261/Pressacademia.2019.1076 \\ PAP-V.9-2019(23)-p.105-108}

Yavuz Selim Balcioglu ${ }^{1}$, Alpaslan Gozel ${ }^{2}$

${ }^{1}$ Gebze Technical University, Department of Management, Gebze, Kocaeli, Turkey ysbalcioglu@gtu.edu.tr, 0000-0001-7138-2972

${ }^{2}$ Gebze Technical University, Technology Transffer Office, Gebze, Kocaeli, Turkey agozel@gtu.edu.tr, 0000-0002-0438-8909

To cite this document

Balcioglu, Y.S., Gozel, A., (2019). Alternatıve management approaches: lean six sigma. PressAcademia Procedia (PAP), V.9, p.105-108 Permemant link to this document: $\mathrm{http} / / /$ doi.org/10.17261/Pressacademia.2019.1076

Copyright: Published by PressAcademia and limited licenced re-use rights only.

\begin{abstract}
Purpose- The aim of this article is to describe Lean Six Sigma and to give information about Lean Six Sigma, which is the main item. Methodology- The pros and cons of Lean Six Sigma are examined. Information about what happened and how it was applied was given. Findings- It is understood that Lean Six Sigma uses it as a tool for leadership development and benefits it provides in process management. Conclusion- Nowadays, new approaches are constantly emerging and disappearing at the same speed. However, Lean Six Sigma will continue to live out of temporary approaches.
\end{abstract}

Keywords: Leadership, lean manufacturing, six sigma, performance management systems, business development JEL Codes: LO, L6, L7.

\section{ALTERNATIF YÖNETIM YAKLAŞIMLARINDAN: YALIN ALTI SIGMA}

\section{ÖZET}

Amaç- Bu makalenin amacı Yalın Altı Sigma'yı tanımlamak ve yapı taşı olan Yalın yöntem ile Altı Sigma hakkında bilgi vermektir Yöntem- Yalın Altı Sigma'nın artıları ve eksileri incelenmiştir. Ne olduğu, nasıl uygulandığı gibi konularda bilgi verilmiştir. Bulgular- Yalın Altı Sigma'nın süreç yönetimlerinde sağlamış olduğu faydalar ve liderlik gelişim aracı olarak kullandığı anlaşılmaktadır. Sonuç- Günümüzde artık yeni yaklaşımlar devamlı ortaya çıkmakta ve aynı hızda yok olmaktadırlar. Ancak Yalın Altı Sigma, gelip geçici yaklaşımların dışında yaşamını sürdürecektir.

Anahtar Kelimeler: Liderlik, yalın üretim, altı sigma, performans yönetim sistemleri, iş geliştirme JEL Kodları: LO, L6, L7.

\section{GíRiş}

Yalın, atık, çeşitlilik ve katma değeri olmayan görevlerin ortadan kaldııımasına odaklanan bir stratejidir. Hem bilgi hem de malzeme akışının optimizasyonu yoluyla sürekli gelişim ve müşteri odaklılığın kültürel bir taahhüdüdür. Altı Sigma, ancak yalın bir taahhüt uygulanmasından sonra gerçekleştirilir ve karmaşık iş sorunlarını çözmek için veri odaklı bir yaklaşımdır. Bir süreci etkileyen değişkenleri daha iyi optimize etmek için anlamak için metodik beş aşamalı bir yaklaşımı kullanır (tanımla, ölç, analiz et, geliştir, kontrol et) (ecnmag.com, 2015)

Yalın Altı Sigma, şirketlerin operasyonlarını düzenlemelerine, değerlernii artırmalarına ve atıkları azaltmalarına yardımcı olmak için Yalın üretim tekniklerinin ve Altı Sigma'nın faydalarını birleştiren bir süreç iyileştirme metodolojisidir (smallbusiness, 2010). Kullanımı imalatta standart hale gelmiştir. Temelde, bir problemi çözmek için bir süreci açıklamayı ifade etmektedir. 


\section{LITERATÜR INCELEMESI}

\subsection{Yalın Yöntemi}

Bütün bir üretim sürecini gerçekten entegre eden ilk kişi Henry Ford oldu. MI, Highland Park'ta, 1913'te, standart üretim ve sürekli üretim ile akış üretimi olarak adlandırdığı sistemi hareket eden bir bant ile sürekli olarak değiştirilebilen parçalarla kurmuştur (lean, 2016).

Ford, özel amaçı makineler kullanarak ve birkaç dakika içinde araca giren bileşenleri imal etmek ve birleştirmek için önceden hazırlanmış göstergeleri kullanarak üretim aşamalarını oluşturmuştur ve kusursuz bir şekilde doğrudan parçaya tam oturan bir yapı kurmuştur. Bu, Amerikan Sistemi için devrim niteliğinde bir kırılma olmuştur(Alizon, Shooter, \& Simpson, 2009).

Dünya, T modeli dışında çeşitlilik istediğinde, Ford yolunu kaybetmekteydi. Diğer otomobil üreticileri, her biri birçok seçeneğe sahip olan pek çok modele duyulan ihtiyacı karşılamaktaydılar. Zamanla, imalat atölyelerinde daha hızlı çalışan, daha büyük makinelerle doldurdular; işlem adımı başına maliyetleri düşürdüler, ancak nadiren (motor işleme hatları gibi - tüm işlem adımlarının olabileceği durumlar hariç) üretim zamanlarını ve stokları sürekli olarak artırdılar(Adeppa, 2015)

Kiichiro Toyoda, Taiichi Ohno ve Toyota'daki diğerleri bu duruma ilk olarak 1930'larda ve daha sonra II. Dünya Savaşı'nın bitişi ile birlikte yoğun bir şekilde ortaya çıkan ihtiyacı, değişimi , bir dizi basit yeniliklerin süreç akışında sürekliliği sağlamayı daha da mümkün kılabileceklerini fark ettiler. Bu nedenle Ford'un orijinal düşüncesinin üzerine Toyota Üretim Sistemini icat ettiler(Marksberry, 2011).

Bu sistem özünde imalat mühendisinin odağını bireysel makinelerden ve bunların kullanımlarından alarak toplam işlem boyunca ürünün akışına kaydırdı. Toyota, ihtiyaç duyulan gerçek hacim için makineleri doğru boyutlandırarak, makineleri işlem sırasına göre sıralayarak, hızlı kurulumlara öncülük ederek her bir makinenin çok sayıda parça numarasına sahip küçük hacimler üretebilmesine karar verdi. Malzemeler için mevcut ihtiyaçlarının bir önceki adımını bildirirken, değişen müşteri isteklerine cevap vermek için düşük maliyetli, yüksek çeşitlilik, yüksek kalite ve çok hızlı üretim süreleri elde etmek mümkün olmaktadaydı. Bu sistem ile birlikte bilgi yönetimi çok daha basit ve daha doğru yapılabilmekteydi.

Yalın düşünce süreci, James P. Womack, Daniel Roos ve Daniel T. Jones tarafından Dünyayı Değiştiren Makine (1990) kitabında ayrıntılı olarak tanımlanmıştır. yalın yönetim sistemi beş aşamaya ayrılmaktadır(Womack, Jones, \& Roos, 1992):

1. Müşteri tarafından istenen değeri belirtin

2. Bu değeri sağlayan her ürün için değer akışını belirleyin boşa harcanan adımların tümüyle (genellikle ondan dokuzu) mücadele edin

3.Ürünekatma değer sağlayan adımları sürekli olarak yenileyin

4.Sürekli akışın mümkün olduğu tüm adımlar arasında çekme işlemini yapın

5.Müşteriye hizmet etmek için gereken adımların sayısı, zaman ve bilgi miktarı sürekli düşecek şekilde mükemmelliği yönetin

Bugün yalın yönetim sisteminin geldiği nokta, dünyanın önde gelen şirketlerinden Toyota, toplam satış anlamında dünyanın en büyük otomobil üreticisi olmayı başarmıştır. Her küresel pazarda artan satış ve pazar paylarına bakıldığında elde ettiği başarı yalın girişimin gücünün en güçlü kanıtı olarak görülmektedir.

Bu devam eden başarı, son 20 yılda yalın düşünce hakkında daha fazla bilgi için muazzam bir talep yaratmıştır.

Yalın düşünce dünyadaki her ülkeye yayılmaya devam ettikçe, liderler aynı zamanda üretimin ötesindeki araçları ve prensipleri, lojistik ve dağıtım, hizmetler, perakende satış, sağlık, inşaat, bakım ve hatta hükümetlere uyarlanmaktadır. Gerçekten de, yalın bilinç ve yöntemler bugün tüm sektörlerdeki üst düzey yöneticiler ve liderler arasında kök salmaya başlamıştır.

\subsection{Altı Sigma Yöntemi}

Sigma; Yunan alfabesinin onsekizinci harfidir. Büyük harf sigma $\left(\sum\right)$, toplam simgesi olarak kullanılır ve küçük harf sigma ( $\left.\sigma\right)$ ise istatistik analizlerinde standart sapmanın simgesi olarak kullanılmaktadır. Sigma; bir sürecin mükemmellikten ne kadar saptığının ölçülmesini sağlamaktadır (Delsanter, 1992)

1890 'lar ve 1900'lerin başında önce Frederick Taylor'un ortaya koyduğu zaman ve hareket etüdleri, 1920'lerde Walter Shewkart'ın üretimde kalitenin kontrolüne ilişkin istatistiksel yaklaşımlar uygulaması başlangıç noktası olmuştur. İkinci Dünya savaşı' ndan sonra işletme yöneticileri kalite kontrol programlarına ilgi göstermeye başlamışlardır. E. Deming ve Joseph Juran 1953'te kalite kontrol sistemini Japonya'ya getirmişlerdir. Bununla birlikte Japonya'da kalitenin gelişimi gözlemlenmiştir. Daha sonra 1970'lerde bir japon şirketi olan Matsushita'ya, Amerikan şirketi olan Motorola'nın Quasar adlı televizyon şirketini, çok fazla oranının getirdiği verimsizlikten dolayı satması ve bunun üzerine Matsushita'nın fabrikanın çalışmasında hızlı ve etkili değişikliklere gidip buradaki hata oranını \%150'den \%3'e düşürmesiyle başlamıştır. Bu olaydan sonra Motorola çalışanları, japonların bu başarısının altında yatan nedenleri araştırmışlardır. Elde ettikleri sonuç olarak; üretilen ürünün kalitesinden ziyade ürünün süreç kalitesiyle ilişkisinin bu başarıyı sağladığını fark etmişlerdir. 1980'lerin başında Motorola yönetim kurulu başkanı Robert Galvin'in başlattığı çalışmayla birlikte Motorola performans boyutunda gelişmeye başlamıştır. Burada Galvin'in asıl amacı yeni ortaya çıkan bu sistemi kendi ürettiği telefonlanların kalitesini arttırmayı hedeflemiştir. Galvin ve ekibi uygulama çıktılarında ürünün ömür süresindeki kullanım alanındaki performansıyla, imalat aşamasında ürünün yeniden işlem görmesi arasında ilişki olduğunu keşfettiler. Galvin'in ekibinde yer alan istatistikçi olan Bill Smith'in oluşturduğu 4 aşamalı problem çözme yaklaşımı olan MAIC'i (ölçme, analiz, geliştirme, kontrol) geliştirdi. Daha sonra bu 4'lü yöntem, altı sigma seviyesine ulaşmak için kullanılan bir problem çözme yöntemi olmuştur. 1987 yılında Galvin, Motorola'da şirketin uzun dönemli politikasını belirleyen "altı sigma kalite programı" adlı yeni kalite programını başlattı. 
Kabul edilen kalite programında 6 sigma günümüze kadar gelmiştir. 1995'in sonlarında General Electric Ceo'su Jack Welch, altı sigmayı tüm destek ve liderlik sistemleriyle firmada uygulamaya başladı(Coronado \& Antony, 2002).

General Electric'de 1998 yılından itibaren çalışanların performans değerlendirmesi de Altı Sigma uygulamaları ile ölçülmeye başlanmıştır. Altı sigma eğitimleri teşvik edilmiştir. Bunun için Altı Sigma eğitimi almamış bir çalışan, statusu yada uzmanlıkları ne olursa olsun kıdem artışı veya yönetim kademesinde bir pozisyon için değerlendirilmelere alınmamaktadır. Sayısal veriler incelendiğinde Motorola'nın 19 yılda elde ettiği getiri 11 milyar dolar civarındadır. Geçmiş verilere bakıldığında Motorola dünya çapındaki verimliliğini 3 katına çıkarmıştır(Pepper \& Spedding, 2010).

Altı Sigma yöntemini uygulayan şirketler, süreçlerinin verimliliğini sigma seviyesi adı verilen bir endeksle izlemektedirler. Sigma seviyesiyle; ürün başına hata, kalitesizlik maliyeti, çevrim zamanı ve verimlilik gibi faktörler arasında sıkı bir ilişki bulunmaktadır. Bir milyon fırsattaki hata sayısı (DPMO), bir Altı Sigma metriğidir. Bu metrikle, bir milyon çıktıdaki hatalı ürün adedi hesaplanır ve Altı Sigma'nın amacı olan DPMO’nun (milyon fırsatta hata sayısı) 3.4'ten düşük olması için çalışmalara yapılır. Bir sürecin Altı Sigma kalite düzeyinde olması demek, elde edilen ürün veya hizmette bir milyonda en fazla 3.4 adet hataya rastlanması demektir (Antony, Jiju Antony, Kumar, \& Rae Cho, 2007)

\subsection{Yalın Altı Sigma Yöntemi}

Yalın Altı Sigma, müşteri memnuniyetini artıran ve sonuç olarak daha iyi sonuçlar elde eden süreç performansını artıran bir iş stratejisi ve metodolojisidir. Yalın Altı Sigma, değişim süreçleri için kavramlar, yöntemler ve araçlar sunar. Yalın Altı Sigma bu nedenle liderleri rolleri ve liderlik değişikliklerine hazırladığı etkili bir liderlik geliştirme aracıdır. Yalın Altı Sigma önceki yaklaşımlardan daha iyi çalışır, çünkü süreç iyileştirmenin insani ve süreç yönlerini bütünleştirir (Snee, 2010).

Altı Sigma, sonuçların alınmasında net bir odaklanma sağlar. İş etkisinin tespiti metodolojinin bir parçasıdır. Alt çizgi etkisi tanımlanmadıkça Yalın Altı Sigma projesi onaylanmamıştır. Alt çizgi etkisi, kalite uzmanı Joseph Juran'ın dilinin para olduğuna işaret ettiği için üst yönetimin dikkatini çekmektedir.

İşletmelerin başarılı olabilmesi Yalın Altı Sigma tekniklerini doğru bir şekilde uygulamalarına bağlıdır. Söz konusu başarıya ulaşmak için firma ve işletmelerin organizasyonel strateji ile bağlantılı projelerle işe başlamaları gerekmektedir(Firuzan ve ark.,2012).Bunun için de DMAIC metodolojisi kullanılmaktadır. Beş aşamalı iyileştirme süreci: (DMAIC) dizileri ve linkleri tanımlayın, ölçün, analiz edin, iyileştirin, kontrol edin (DMAIC) süreçleri iyileştirmede etkili olduğu tespit edilen istatistiksel ve diğer araçları kilit bir şekilde ele alın. Tamamen yeni olmamakla birlikte (De Mast \& Lokkerbol, 2012), hiçbir iyileştirme süreci bu kadar etkili olmamıştır.

Bu üç özellik: insanın entegrasyonu ve iyileştirme süreç unsurları; net sonuç elde etmeye odaklanın; ve Yalın Altı Sigma'nın Yalın Yönleri ile birleştirildiğinde, iyileştirme araçlarını genel bir yaklaşıma sıralayan ve bağlayan bir yöntem, diğer iyileştirme girişimleri tarafından kullanılan istihdam yaklaşımlarından daha iyi bir dağıtım yaklaşımı üretmektedir.

\section{SONUÇ VE ÖNERILER}

İşletme boyutunda, işletme kültürünün bir parçası haline geldiğinde, tüm çalışanlar tarafından benimsenmiş ve kabul edilmiş bir felsefe olacaktır. Bundan dolayı iş süreçlerinde elde edilen iyileştirme ve verimliliğin arttırılması, oluşacak problemlerin tanımlanması, bunların analizinden kontrol aşamasına kadar giden süreç etkinliğinin artması sağlanabilecektir.

1970'lerden sonra günümüze kadar altı sigma uygulayan işletmeler başta finans olmak üzere, üretimden, insan kaynaklarından pazarlamaya kadar bütün iş süreçlerinde iyileştirmeler sağladıkları ve verimliliklerini arttırdıkları görülmektedir. Yalın yapının altı sigma'ya dahil edilmesinden sonra ise artık işletmelerin her kademelerinde oluşan hataları azaltıp, iyileştirme ve gelişmelerinde olabilecek en kusursuz biçimine dönüşmüştür.

Günümüzde artık yeni yaklaşımlar devamlı ortaya çıkmakta ve aynı hızda yok olmaktadırlar. Ancak Yalın Altı Sigma, gelip geçici yaklaşımların dışında yaşamını sürdürecektir. Bunda en etkili nedenlerden biri ise maliyeti düşürmek ve nakit akışını korumak için devletlerin, şirketlerin bu yaklaşımı teşvik etmeleridir.

\section{KAYNAKÇA}

Adeppa, A. (2015). A Study on Basics of Assembly Line Balancing. International Journal on Emerging Technologies.

Alizon, F., Shooter, S. B., \& Simpson, T. W. (2009). Henry Ford and the Model T: lessons for product platforming and mass customization. Design Studies. https://doi.org/10.1016/j.destud.2009.03.003

Antony, J., Jiju Antony, F., Kumar, M., \& Rae Cho, B. (2007). Six sigma in service organisations. International Journal of Quality \& Reliability Management. https://doi.org/10.1108/02656710710730889

Coronado, R. B., \& Antony, F. (2002). Critical success factors for the successful implementation of six sigma projects in organisations. TQM Magazine. https://doi.org/10.1108/09544780210416702

De Mast, J., \& Lokkerbol, J. (2012). An analysis of the Six Sigma DMAIC method from the perspective of problem solving. International Journal of Production Economics. https://doi.org/10.1016/j.ijpe.2012.05.035

Delsanter, J. (1992). Six sigma. Managing Service Quality: An International Journal. https://doi.org/10.1108/09604529210029353 
ecnmag.com. (2015). No Title. Retrieved from https://www.ecnmag.com/article/2015/06/benefits-lean-six-sigma-methodology-culture lean. (2016). No Title. Retrieved from https://www.lean.org/WhatsLean/History.cfm

Marksberry, P. (2011). The Toyota Way - a quantitative approach. International Journal of Lean Six Sigma. https://doi.org/10.1108/20401461111135028

Pepper, M. P. J., \& Spedding, T. A. (2010). The evolution of lean Six Sigma. International Journal of Quality and Reliability Management. https://doi.org/10.1108/02656711011014276

smallbusiness. (2010). No Title. Retrieved from https://smallbusiness.chron.com/benefits-lean-six-sigma-2010.html

Snee, R. D. (2010). Lean Six Sigma - getting better all the time. International Journal of Lean Six Sigma. https://doi.org/10.1108/20401461011033130

Womack, J. P., Jones, D. T., \& Roos, D. (1992). The machine that changed the world. Business Horizons. https://doi.org/10.1016/00076813(92)90074-J 